\title{
One-Year Angiographic Follow-Up after WEB-SL Endovascular Treatment of Wide-Neck Bifurcation Intracranial Aneurysms
}

\author{
R. Sivan-Hoffmann, DB. Gory, (DR. Riva, (DP.-E. Labeyrie, F. Signorelli, I. Eldesouky, U. Gonike-Sadeh, X. Armoiry, and DF. Turjman
}

\begin{abstract}
BACKGROUND AND PURPOSE: Endovascular coiling of wide-neck intracranial aneurysms is associated with low rates of initial angiographic occlusion and high rates of recurrence. The WEB intrasaccular device has been developed specifically for this indication. To date, there has been no report of the long-term follow-up of a series of patients with aneurysms treated with this type of device, to our knowledge. Our aim was to evaluate a l-year follow-up of angiographic results in a prospective single-center series of patients treated with the WEB-Single-Layer (SL) device.
\end{abstract}

MATERIALS AND METHODS: All patients treated with the WEB-SL device in our center between August 2013 and May 2014 were prospectively included. One-year angiographic outcomes were assessed. Results at follow-up were graded as complete occlusion, neck remnant, or residual aneurysm.

RESULTS: Eight patients with 8 unruptured wide-neck aneurysms were enrolled in this study. Average dome width was 7.5 mm (range, 5.4-10.7 mm), and average neck size was $4.9 \mathrm{~mm}$ (range, 2.6-6.5 mm). One-year angiographic follow-up obtained in all aneurysms included 1 complete aneurysm occlusion (12.5\%), 6 neck remnants (75\%), and 1 aneurysm remnant (12.5\%). Of 8 aneurysms, worsening of aneurysm occlusion was observed in $2(25 \%)$ by compression of the WEB device. There was no angiographic recurrence of initially totally occluded aneurysms. No bleeding was observed during the follow-up period.

CONCLUSIONS: Endovascular therapy of intracranial aneurysms with the WEB-SL device allows treatment of wide-neck aneurysms with a high rate of neck remnant at 1 year, at least partially explained by WEB compression. Initial size selection and technologic improvements could be an option for optimization of aneurysm occlusion in WEB-SL treatment.

ABBREVIATIONS: AcomA = anterior communicating artery; $\mathrm{DL}=$ Dual-Layer; $\mathrm{SL}=$ Single-Layer

$\mathrm{T}$

he WEB aneurysm embolization system (Sequent Medical, Aliso Viejo, California) is an intrasaccular braided device specifically developed for endovascular treatment of wide-neck intracranial aneurysms with the goal of disrupting flow at the aneurysm neck and promoting aneurysmal thrombosis without the need for reconstruction of the entire parent artery segment with a stent. Several types of WEB devices are currently available ${ }^{1}$ : the WEB-Dual-Layer (DL), which is made of 2 layers held together

Received December 20, 2014; accepted after revision March 2, 2015

From the DHU IRIS, Departments of Interventional Neuroradiology (R.S.-H., B.G., R.R., P.-E.L., I.E., U.G.-S., F.T.) and Neurosurgery (F.S.), Hôpital Neurologique Pierre Wertheimer, Hospices Civils de Lyon, Lyon, France; and Hospices Civils de Lyon (X.A.), Délégation à la Recherche Clinique et à l'Innovation, Cellule Innovation/ UMR-CNRS 5510/MATEIS, Lyon, France.

R.S.-H. and B.G. contributed equally to this work.

Please address correspondence to Benjamin Gory, MD, MSc, DHU IRIS, Department of Interventional Neuroradiology, Hôpital Neurologique Pierre Wertheimer, Hospices Civils de Lyon, 59 Boulevard Pinel, 69677 Bron, France; e-mail: benjamin.gory@chu-lyon.fr

http://dx.doi.org/10.3174/ajnr.A4457 and creating 2 compartments, and the WEB-Single-Layer (SL), which is a single-layer device creating only 1 compartment. Only a few studies on the treatment of intracranial aneurysms by using the WEB-DL have been published, ${ }^{2-5}$ and to date, only a single published article on aneurysms treated with WEB-SL reported a series including any anatomic follow-up. ${ }^{6}$ We recently published the 6-month clinical and anatomic outcomes of WEB-SL endovascular treatment. ${ }^{7}$

The purpose of this study was to evaluate the 1-year angiographic results of patients managed with the WEB-SL device in a prospective single-center series.

\section{MATERIALS AND METHODS Population}

All patients treated in the Neurologic Pierre Wertheimer Hospital in Lyon (France) with the WEB-SL device for intracranial unruptured aneurysms between August 2013 and May 2014 were prospectively included. The indication for treatment and the technique chosen (surgery or endovascular) were decided by a 

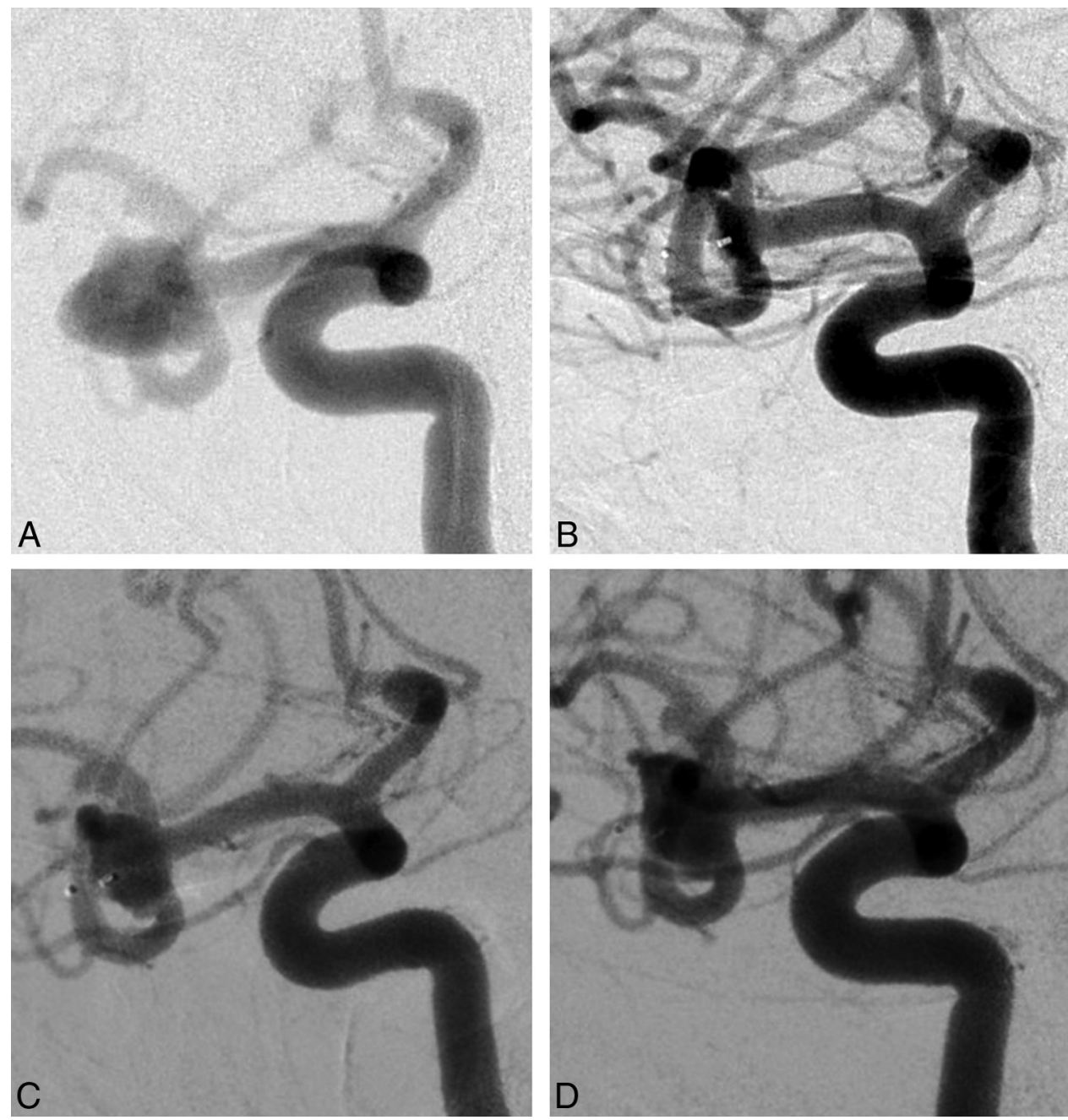

FIG 1. Case 1 (patient 5) involves a right unruptured MCA aneurysm in a 44-year-old woman. A, Subtracted angiography of the internal carotid artery shows a wide-neck MCA aneurysm. The inferior branch is emerging from the neck of the aneurysm. $B$, Subtracted angiography of the internal carotid artery at the end of the procedure shows a small neck remnant. $C$, Subtracted angiography of the internal carotid artery at 6 months shows a growing neck remnant by WEB compression. $D$, Subtracted angiography of the internal carotid artery at 12 months shows a worsening of the neck remnant compared with the one at 6 months.

multidisciplinary team according to the aneurysm characteristics (size, neck, and width). In the case of an endovascular approach, wide-neck aneurysms were treated with an intrasaccular device. The protocol was approved by the local ethics committee. Written informed consent was obtained from each patient or legal representative before entry into the study.

\section{Endovascular Procedure}

No preinterventional medication was administered. The procedure was performed with the patient under general anesthesia and full heparinization (bolus of $80 \mathrm{IU} / \mathrm{kg}$ ). Cerebral angiograms were obtained via a femoral approach. 3D angiography was performed to determine the size of the dome and length and neck of the aneurysm.

A VIA Microcatheter (Sequent Medical) was then inserted coaxially over a 0.014 -inch microguidewire to reach within the aneurysm. The VIA 27 was used for the WEB-SL with a width of $\leq 9$ $\mathrm{mm}$, and a VIA 33 , for a width of $\geq 10 \mathrm{~mm}$. After adequate positioning of the WEB device inside the aneurysmal sac, we performed a control angiogram to evaluate the position of the device and the flow stagnation inside. If the position was not satisfactory, the device was resheathed and repositioned. When the size was found to be incorrect, the device was resheathed and replaced by a different-sized WEB. At the end of the procedure, $500 \mathrm{mg}$ of aspirin was administrated intravenously. Oral aspirin $(75 \mathrm{mg})$ was continued for another month to prevent delayed thromboembolic events due to the contact between the blood and the device covering a wide neck.

\section{Clinical Follow-Up}

Bleeding or rebleeding occurrence during the period of follow-up was evaluated.

\section{Outcome Evaluation}

Angiograms were obtained in anteroposterior, lateral, and working projections before the treatment, immediately after, at 6 months, and at 1-year follow-up. A simplified 3-point Raymond scale (complete occlusion, neck remnant, aneurysm remnant) was used to assess the results of the procedure. ${ }^{8}$ Adequate aneurysm occlusion was defined as total aneurysm occlusion or neck remnant. 

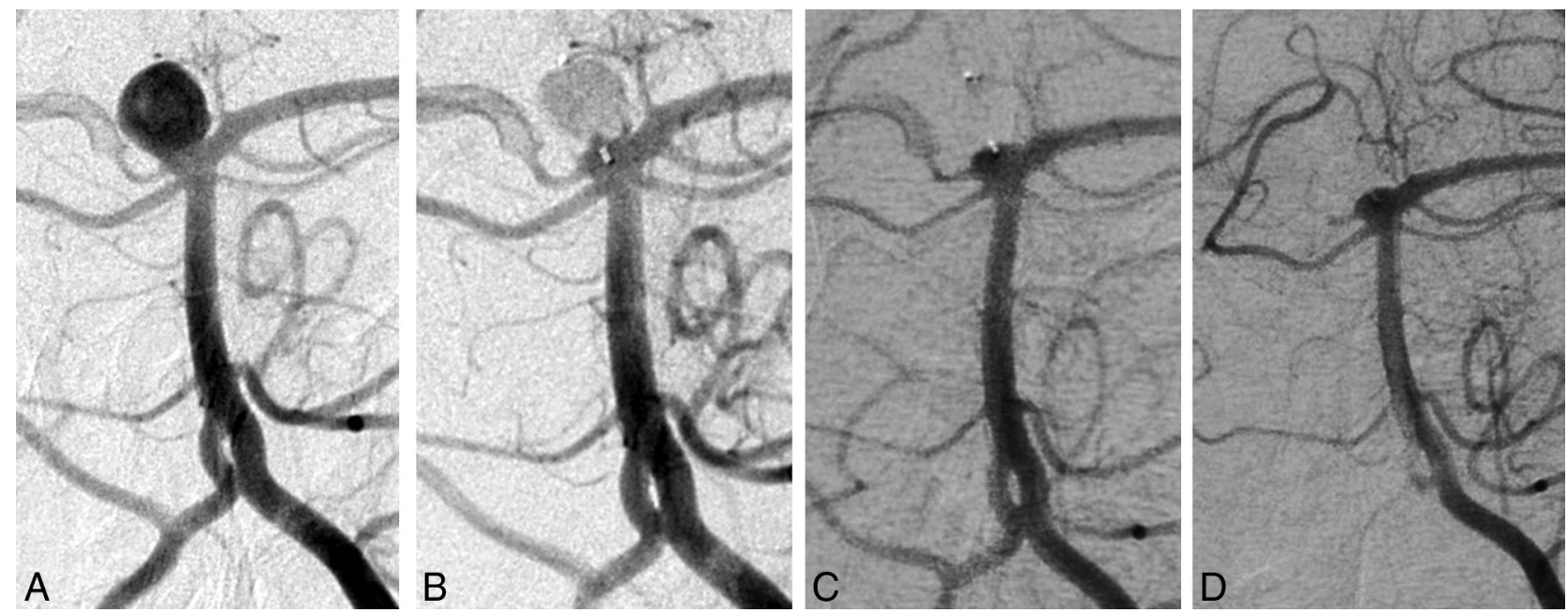

FIG 2. Case 2 (patient 6) involves a right unruptured basilar tip aneurysm in a 59-year-old man. A, Subtracted angiography of the left vertebral artery shows a basilar tip aneurysm. $B$, Subtracted angiography of the left vertebral artery at the end of the procedure shows complete aneurysm occlusion. Subtracted angiographies of the left vertebral artery at 6 months $(C)$ and 12 months $(D)$ show near-complete aneurysm occlusion with a small compression of the proximal WEB portion.

Aneurysm characteristics and angiographic outcome at 6 and 12 months

\begin{tabular}{|c|c|c|c|c|c|c|c|c|c|c|}
\hline \multirow[b]{2}{*}{ Patient No. } & \multirow[b]{2}{*}{ Age (yr), Sex } & \multirow[b]{2}{*}{ Location } & \multirow[b]{2}{*}{ WEB Type } & \multirow[b]{2}{*}{$\mathrm{D}(\mathrm{mm})$} & \multirow[b]{2}{*}{$\mathrm{T}(\mathrm{mm})$} & \multirow[b]{2}{*}{$\mathrm{N}(\mathrm{mm})$} & \multirow[b]{2}{*}{ D/N (Ratio) } & \multirow[b]{2}{*}{ WEB Size (mm) } & \multicolumn{2}{|c|}{ Angiographic Outcomes } \\
\hline & & & & & & & & & 6 Months & 1 Year \\
\hline 1 & $45, M$ & AcomA & SL & 8.9 & 5.8 & 5.3 & 1.7 & $7 \times 5$ & NR & NR \\
\hline 2 & $59, M$ & MCA & SL & 6.2 & 7.5 & 5.1 & 1.2 & $9 \times 5$ & AR & AR \\
\hline 3 & $56, M$ & AcomA & SL & 7.9 & 6.9 & 2.6 & 3.0 & $7 \times 5$ & NR & $N R(w)$ \\
\hline 4 & $53, \mathrm{~F}$ & MCA & SL & 5.7 & 4.6 & 4.7 & 1.2 & $6 \times 4$ & NR & NR \\
\hline 5 & $44, \mathrm{~F}$ & MCA & SL & 8.9 & 8.2 & 6.5 & 1.4 & $8 \times 4$ & NR & $N R(w)$ \\
\hline 6 & $59, M$ & Basilar tip & SLS & 6.1 & 5.9 & 4 & 1.5 & $7 \times 4$ & NR & NR \\
\hline 7 & $65, M$ & AcomA & SL & 10.7 & 6.4 & 5.6 & 1.9 & $6 \times 3$ & $C$ & $C$ \\
\hline 8 & $68, F$ & AcomA & $S L$ & 5.4 & 5.1 & 5.1 & 1.1 & $7 \times 6$ & NR & NR \\
\hline
\end{tabular}

Note:-D indicates dome; $\mathrm{T}$, transverse diameter; $\mathrm{N}$, neck; C, complete aneurysm occlusion; NR, neck remnant; AR, aneurysm remnant; $\mathrm{w}$, worsening; SLS, Single-Layer Spheric.

\section{RESULTS}

Eight patients ( 5 men and 3 women) with 8 wide-neck intracranial aneurysms were prospectively included during the study period. The mean age of these patients was 58 years (range, $44-70$ years). Three aneurysms were located at the middle cerebral artery bifurcation; 4, at the anterior communicating artery (AcomA); and 1 , at the basilar tip artery. On the working projections, the mean width of the aneurysm sac (dome) was $7.5 \mathrm{~mm}$ (range, 5.4-10.7 $\mathrm{mm}$ ), the mean transversal diameter was $6.3 \mathrm{~mm}$ (range, $4.6-8.2 \mathrm{~mm}$ ), and the mean diameter of the aneurysm neck was $4.9 \mathrm{~mm}$ (range, $2.6-6.5 \mathrm{~mm}$ ). All procedures required only 1 WEB-SL implant with no additional devices.

\section{Clinical Outcomes}

All patients initially included were followed up. No death or bleeding was reported during the follow-up period. No patient experienced even slight worsening at 1 year. The permanent 1 -year morbidity rate was $0 \%$, and the mortality rate was $0 \%$.

\section{Angiographic Outcomes}

Angiograms at 1-year follow-up are detailed in the Table. Angiographic follow-up at 1 year was obtained in all patients, including 1 complete aneurysm occlusion (12.5\%), 6 neck remnants (75\%), and 1 incomplete aneurysm occlusion (12.5\%). Adequate aneurysm occlusion (total occlusion or neck remnant) was observed in
$87.5 \%$. Among the 6 neck remnants at 6 - and 12 -month followup, 3 were $\leq 2 \mathrm{~mm}$.

In 2 cases $(25 \%)$, the aneurysm remnants increased at 1-year follow-up with WEB compression. No retreatment was performed.

\section{DISCUSSION}

In this preliminary study, we assessed the 1-year angiographic results of patients managed only with the WEB-SL intrasaccular device.

Although adequate aneurysm occlusion was achieved in most cases $(87.5 \%)$, the anatomic results are in some ways disappointing, owing to the high rate of neck remnant and recanalization in this small series of 8 patients. In fact, we observed a neck remnant in $75 \%$ of cases with half of them a size of superior $3 \mathrm{~mm}$; however, a majority of cases were challenging aneurysms with wide necks. The average dome width was $7.5 \mathrm{~mm}$, and average neck size was $4.9 \mathrm{~mm}$ in our series. Other authors have observed this high rate of neck remnant at short-term follow-up with the WEB-DL device. In Pierot et al, ${ }^{4}$ adequate occlusion (total occlusion or neck remnant) was observed in $83.3 \%$ of 33 treated aneurysms. In Lubicz et $\mathrm{al}^{3}{ }^{3}$ in a series of 18 treated wide-neck bifurcations aneurysms, 2 complete occlusions, 15 near-complete occlusions (89.5\% adequate occlusion), and 2 incomplete occlusions were 

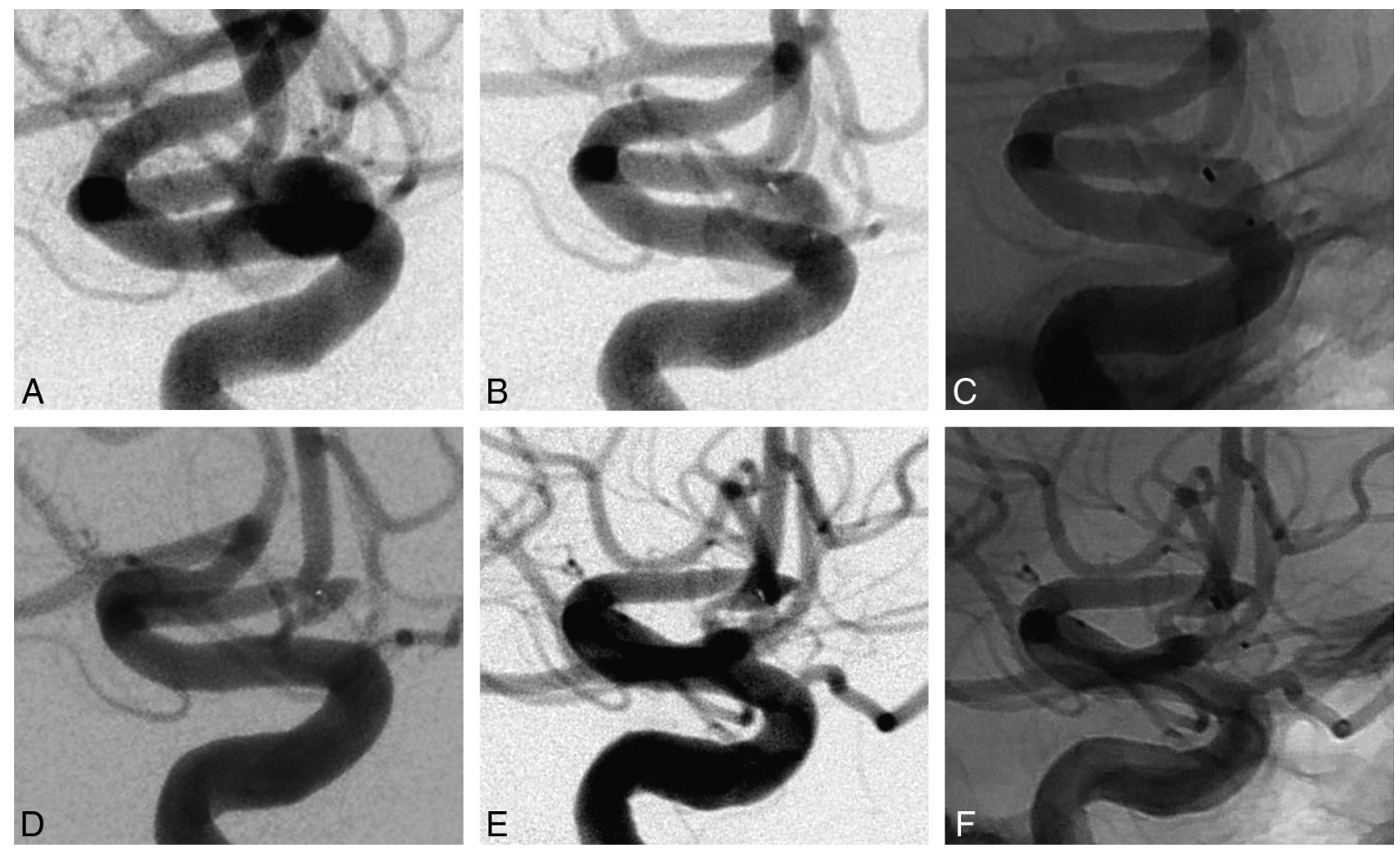

FIG 3. Case 3 (patient 1) involves an AcomA aneurysm in a 45-year-old man. A, Subtracted angiography of the internal carotid artery shows an AcomA aneurysm. The inferior branch is emerging from the neck of the aneurysm. $B$ and $C$, Subtracted and unsubtracted angiography of the internal carotid artery at the end of the procedure shows a small neck remnant. $D$, Subtracted angiography of the internal carotid artery at 6 months shows near-complete aneurysm occlusion with a neck remnant size of $<2 \mathrm{~mm}$. $E$ and $F$, Subtracted angiography of the internal carotid artery at 12 months shows a near-complete occlusion with a neck remnant that is stable in size. No compression of the device was observed by digital subtraction angiography.

reported at 6-month angiographic follow-up. Similar findings were also reported in a large prospective French series of 85 patients $(92.3 \%) .^{2}$ To date, few results of the treatment with the WEB-SL device have been published, to our knowledge. Pierot et $\mathrm{al}^{6}$ reported immediate and 1 -month safety results after endovascular treatment of intracranial aneurysms by using the WEB-DL and WEB-SL/Single-Layer Spheric device. We recently reported the 6-month efficacy of a WEB-DL and WEB-SL for the treatment of 10 wide-neck anterior communicating artery aneurysms. ${ }^{1}$ Five aneurysms were treated with the WEB-SL; we observed 2 complete aneurysm occlusions and 3 neck remnants at 3 to 6-month follow-up.

At 1-year angiographic follow-up, we reported a $75 \%$ rate of neck remnants and found the remnants to increase in size in 2 neck remnant cases. Our high rate of neck remnants seems to be at least partially explained by the compression and deformation of the WEB-SL device. This frequency of neck remnant is also probably due to the shape of the WEB. The proximal surface of the WEB is not flat but has a recess, which is concave from the direction of the parent artery. It was designed to minimize protrusion of the proximal marker in the parent vessel, but it contributes to the appearance of a neck remnant so that in the 1-year follow-up, we noticed advanced neck size, along with further compaction of the device. In some cases, the device was found at a different angle than on deployment, and in others, the neck was bulging toward the device. Cognard and Januel ${ }^{9}$ recently reported similar findings in a series of 15 consecutive patients. Compression of the
WEB cage (12 WEB-DLs and 3 WEB-SLs) was observed at first follow-up (3-6 months) in 8 of $14(57.2 \%)$ patients and in an additional 3 of 7 patients $(42.8 \%)$ at second follow-up (18 \pm 3 months). The last angiography showed complete occlusion in 1 of $14(7.2 \%)$, neck remnant in 8 of $14(57.2 \%)$, and residual aneurysm in 5 of $14(35.7 \%)$ patients.

In this specific situation of challenging aneurysms with a wide neck at the middle cerebral artery or anterior communicating artery locations, stent- and balloon-assisted coiling are 2 wellestablished techniques. ${ }^{10-12}$ Compared with balloon-assisted coiling, stent-assisted coiling was found to yield higher rates of aneurysm obliteration and progression of occlusion at followup. ${ }^{13}$ However, compared with the WEB device, the major disadvantage of using a stent is the need for dual antiplatelet therapy, which seems to be associated with a high incidence of adverse events and outcomes. ${ }^{11,14,15}$ A novel device (pCONus aneurysm implant; phenox, Bochum, Germany) has recently been developed to improve the safety of endovascular treatment of wide-neck aneurysms. To date, few results of aneurysms treated with the pCONus have been reported in the literature. ${ }^{16,17}$ In a series of 40 consecutive MCA aneurysms (mean dome size, $7.7 \mathrm{~mm}$; mean neck size, $5.6 \mathrm{~mm}$ ), Gory et $\mathrm{al}^{17}$ reported stable or improved results in all cases except 3 patients with a mean follow-up of 6.8 months, including $48.5 \%$ complete occlusions (16/33), 30.3\% neck remnants (10/33), and $21.2 \%$ aneurysm remnants $(7 / 33)$.

AJNR Am J Neuroradiol 36:2320-24 Dec 2015 www.ajnr.org 


\section{CONCLUSIONS}

Endovascular therapy of intracranial aneurysms with the WEB-SL device allows the treatment of wide-neck aneurysms with a high rate of neck remnant at 1 year, at least partially explained by WEB compression. Initial size selection and technologic improvements could be an option to optimize the aneurysm occlusion in WEB-SL treatment.

Disclosures: Francis Turjman-UNRELATED: Consultancy: Covidien,* Codman,* Stryker*; Grants/Grants Pending: Covidien*; Payment for Development of Educational Presentations: Codman,* Stryker*; Travel/Accommodations/Meeting Expenses Unrelated to Activities Listed: Covidien,* Stryker.* *Money paid to the institution.

\section{REFERENCES}

1. Gherasim DN, Gory B, Sivan-Hoffmann R, et al. Endovascular treatment of wide-neck anterior communicating artery aneurysms using WEB-DL and WEB-SL: short-term results in a multicenter study. AJNR Am J Neuroradiol 2015;36:1150-54 CrossRef Medline

2. Papagiannaki C, Spelle L, Januel AC, et al. WEB intrasaccular flow disruptor-prospective, multicenter experience in 83 patients with 85 aneurysms. AJNR Am J Neuroradiol 2014;35:2106-11 CrossRef Medline

3. Lubicz B, Mine B, Collignon L, et al. WEB device for endovascular treatment of wide-neck bifurcation aneurysms. AJNR Am J Neuroradiol 2013;34:1209-14 CrossRef Medline

4. Pierot L, Klisch J, Cognard C, et al. Endovascular WEB flow disruption in middle cerebral artery aneurysms: preliminary feasibility, clinical, and anatomical results in a multicenter study. Neurosurgery 2013;73:27-34; discussion 34-45 CrossRef Medline

5. Pierot L, Liebig T, Sychra V, et al. Intrasaccular flow-disruption treatment of intracranial aneurysms: preliminary results of a multicenter clinical study. AJNR Am J Neuroradiol 2012;33:1232-38 CrossRef Medline

6. Pierot L, Moret J, Turjman F, et al. WEB treatment of intracranial aneurysms: feasibility, complications, and 1-month safety results with the WEB DL and WEB SL/SLS in the French Observatory. AJNR Am J Neuroradiol 2015;36:922-27 CrossRef Medline

7. Bozzetto Ambrosi P, Gory B, Sivan-Hoffmann R, et al. Endovascular treatment of bifurcation intracranial aneurysms with the WEB SL/ SLS: 6-month clinical and angiographic results. Interv Neuroradiol 2015;21:462-69. CrossRef Medline

8. Raymond J, Guilbert F, Weill A, et al. Long-term angiographic recurrences after selective endovascular treatment of aneurysms with detachable coils. Stroke 2003;34:1398-403 CrossRef Medline

9. Cognard C, Januel AC. Remnants and recurrences after the use of the WEB intrasaccular device in large-neck bifurcation aneurysms. Neurosurgery 2015;76:522-30; discussion 530 CrossRef Medline

10. Gory B, Kessler I, Seizem Nekiri G, et al. Initial experience of intracranial aneurysm embolization using the balloon remodeling technique with Scepter C, a new double-lumen balloon. Interv Neuroradiol 2012;18:284-87 CrossRef Medline

11. Gory B, Rouchaud A, Saleme S, et al. Endovascular treatment of middle cerebral artery aneurysms for 120 nonselected patients: a prospective cohort study. AJNR Am J Neuroradiol 2014;35:715-20 CrossRef Medline

12. Gory B, Klisch J, Bonafé A, et al. Solitaire AB stent-assisted coiling of wide-necked intracranial aneurysms: mid-term results from the SOLARE Study. Neurosurgery 2014;75:215-19; discussion 219 CrossRef Medline

13. Chalouhi N, Starke RM, Koltz MT, et al. Stent-assisted coiling versus balloon remodeling of wide-neck aneurysms: comparison of angiographic outcomes. AJNR Am J Neuroradiol 2013;34: 1987-92 CrossRef Medline

14. Piotin M, Blanc R, Spelle L, et al. Stent-assisted coiling of intracranial aneurysms: clinical and angiographic results in 216 consecutive aneurysms. Stroke 2010;41:110-15 CrossRef Medline

15. Bartolini B, Blanc R, Pistocchi S, et al. "Y" and " $X$ " stent-assisted coiling of complex and wide-neck intracranial bifurcation aneurysms. AJNR Am J Neuroradiol 2014;35:2153-58 CrossRef Medline

16. Aguilar-Pérez M, Kurre W, Fischer S, et al. Coil occlusion of wideneck bifurcation aneurysms assisted by a novel intra- to extra-aneurysmatic neck-bridging device (pCONus): initial experience. AJNR Am J Neuroradiol 2014;35:965-71 CrossRef Medline

17. Gory B, Aguilar-Pérez M, Pomero E, et al. pCONus device for the treatment of wide-neck middle cerebral artery aneurysms. AJNR Am J Neuroradiol 2015 Jul 23. [Epub ahead of print] CrossRef Medline 